RESEARCH HIGHLIGHTS

\section{URLs}

Meningitis: http://www.cdc.gov/ ncidod/diseases/submenus/sub_ meningitis.htm

Streptococcus pneumoniae: http:// www.ncbi.nlm.nih.gov/entrez/query.f cgi?db=genomepri\&cmd=Retrieve\& dopt=Overview\&list_uids $=12328$

BACTERIAL PATHOGENESIS

\title{
Dual to the death
}

Streptococcus pneumoniae induces programmed cell death in brainderived endothelial cells through two functionally and morphologically distinct pathways that occur over different time frames, according to a recent report published in the Journal of Clinical Investigation.

Although generally a commensal microorganism of the upper respiratory tract, S. pneumoniae can cause acute meningitis when it finds its way across the blood-brain barrier. Despite the availibility of antibiotics, pneumococcal meningitis has high mortality and morbidity. Using brain microvascular endothelial cells (BMECs) isolated from rats and mice as an in vitro model, a group led by Joerg R. Weber at The Charité

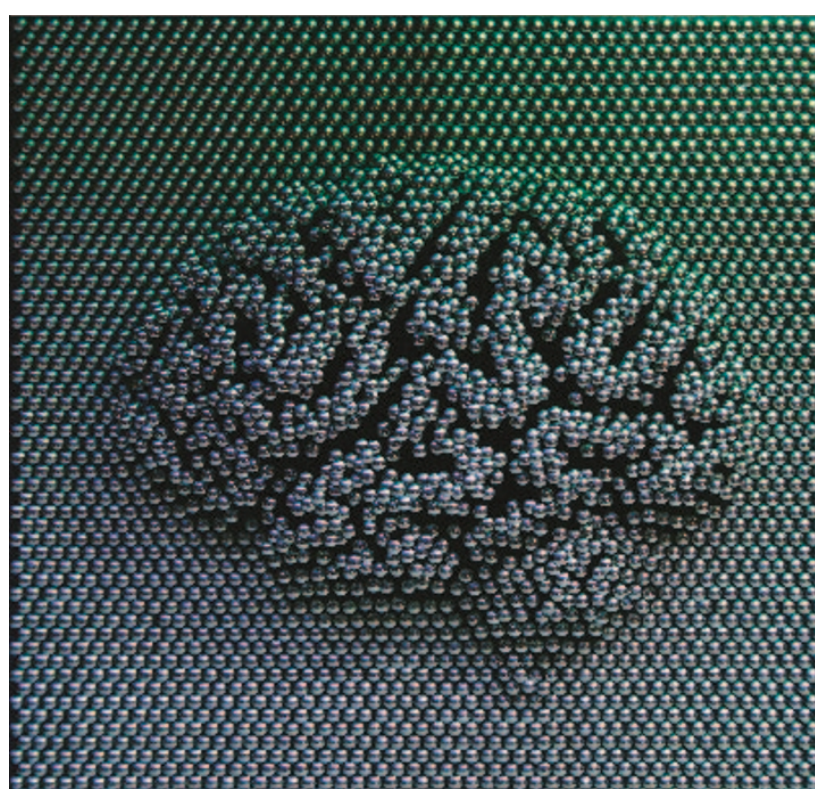

Medical School in Berlin, Germany, investigated the mechanisms through which pneumococci damage and kill endothelial cells of the blood-brain barrier.

Living S. pneumoniae were found to rapidly induce apoptosis-like programmed cell death (PCD), leading to total destruction of the BMEC monolayer within 12 hours. This process was dependent on neurotoxins secreted by the pneumococci, $\mathrm{H}_{2} \mathrm{O}_{2}$ and pneumolysin, as their absence decreased PCD. Mitochondrial damage led to the subsequent release of the mitochondrial apoptosis-inducing factor (AIF) into the cytoplasm, which has been suggested as a potential executor of pneumococcal-induced cell death in other cells. Living pneumococci failed to activate caspases, and this PCD mechanism did not depend on the presence of Toll-like receptors (TLRs).

In addition, pneumococcal cell wall (PCW) was found to induce classical apoptosis in BMECs, causing complete condensation and fragmentation of the nucleus. Apoptosis was induced through TLR-2, a crucial receptor in the innate immune response, and through the activation of caspases (in particular caspase- 3 and caspase-8). This process occurred over a longer time frame than PCD induced by living pneumococci, which could cause disruption of endothelial and neuronal repair during resolution of meningitis.
Taken together, these two pathways contribute to both acute and prolonged damage during meningitis. The PCW-induced mechanism has implications for therapeutic treatment - antibiotics that target the cell wall might well kill S. pneumoniae, but in doing so they also cause further inflammation and tissue destruction through the release of cell-wall debris.

Annie Tremp

\section{(4) References and links}

ORIGINAL RESEARCH PAPER Bermpohl, D. et al. Bacterial programmed cell death of cerebral endothelial cells involves dual death pathways. J. Clin. Invest. 115, 1607-1615 (2005)

\section{FURTHER READING}

Mitchell, T. J. The pathogenesis of streptococcal infections: from tooth decay to meningitis. Nature Rev. Microbiol. 1, 219-230 (2003) 